\title{
Role of Visual Attention in Developmental Dyslexia
}

\author{
Andrea Facoetti ${ }^{1,2}$, Sandro Franceschini ${ }^{1,2}$ and Simone Gori ${ }^{2,3}$ \\ 1. Developmental and Cognitive Neuroscience Lab, Department of General Psychology, \\ University of Padua, via Venezia 8, 35131 Padua, Italy \\ 2. Child Psychopathology Unit, Scientific Institute, IRCCS Eugenio Medea, via don Luigi Monza 20, 23842 \\ BosisioParini, Lecco, Italy \\ 3. Department of Human and Social Sciences, University of Bergamo, Bergamo 24129, Italy
}

\section{Corresponding Authors:}

-Andrea Facoetti, PhD, Department of General Psychology, University of Padua,

Via Venezia 8, Padova 35131, Italy;

Phone +390498276675 ,

Fax +390498276600 .

e-mail address: andreafacoetti@unipd.it

-Simone Gori, PhD, Department of Human and Social Sciences, University of Bergamo, Piazzale S. Agostino 2, Bergamo 24129, Italy.

Phone: (+39) 035-2052-932

Fax: (+39) 035-2052-916

e-mail address: simone.gori@unibg.it 


\section{Introduction}

Attention is a neurocognitive process composed by sub-processes located in several brain areas and controlled by specific neurotransmitters (Petersen \& Posner, 2012). This process aims to select relevant information and modulates sensory processing, perception, memory, and learning. This selection of information processing - based on the combination of perceptual noise exclusion and signal enhancement-is fundamental in developing fine object representations in the brain (see Corbetta \& Shulman, 2011; Petersen \& Posner, 2012; Roelfsema, van Ooyen, \& Watanabe, 2010, for reviews).

Alerting and orienting are the two main processes involved in reading acquisition.Alerting is defined as the multisensory attentional process that increases performance during tasks (Petersen \& Posner, 2012), producing a phasic change in alertness (e.g., Ronconi, Pincham, Szűcs \& Facoetti, 2016). The alerting system can be already measured in infant brain (e.g., Ronconi, Facoetti, et al., 2014).Attention orienting is the ability to select a spatial location (Petersen \& Posner, 2012) or time event (Battelli, PascualLeone, \& Cavanagh, 2007, for a review) inside the sensory field. Attention orienting is described as a spotlight that moves to the attended area (Carrasco, 2011). The attention spotlight is not only oriented in a specific spatiotemporal location, but can also be adjusted in its size (i.e.,zoom-in and zoom-out of focusing attention, e.g., Facoetti, Lorusso, Paganoni, Umiltà, \& Mascetti, 2003; Facoetti \& Molteni, 2000; Facoetti, Paganoni, Turatto, Marzola, \& Mascetti, 2000; Ronconi, Facoetti, et al., 2014; Ronconi, Gori, Ruffino, Molteni, \& Facoetti, 2013; Ronconi et al., 2016). Frontal and parietal areas are the neural substrate of the orienting and focusing of attention (Battelli et al., 2007; Corbetta \& Shulman, 2002; Ronconi, Basso, Gori, \&Facoetti, 2014).Subcortical lateral geniculate nucleus (LGN) and the pulvinar, in the thalamus has also been shown to participate in attentional orienting (Schneider \& Kastner, 2009). 
In this chapter, we will start out with providing a theoretical background on how visual attention may be involved in reading and developmental dyslexia. In addition, research evidence will be summarized on the occurrence of a visual deficit independently from a phonological deficit that is predominantly cited in the literature (see Chapter 12). Explanatory mechanisms for such a visual deficit in dyslexia will also be discussed. Finally, clinical implications will be provided along with a final conclusion.

\section{Theoretical Background}

Individuals with developmental dyslexia (DD) present difficulties with accurate and fluent word recognition and spelling despite adequate instruction, intelligence, and sensory abilities. DD is characterized by difficulties with decoding, while comprehension is more intact (Peterson \& Pennington, 2015).

DD is often associated with an impaired phonological awareness, which refers to the ability to perceive and manipulate the sounds of spoken words (Castles \& Coltheart, 2004). A phonological awareness deficit could impair the ability to map speech sounds onto their homologous visual letters (see Vellutino, Fletcher, Snowling, \& Scanlon, 2004). Impairedphonological awareness is largely assumed to be the core deficit in DD (see Gabrieli, 2009; Peterson \& Pennington, 2015). However, reading acquisition can profoundly refine the neurocognitive organization of the auditory-phonological reading network (see Dehaene, Cohen, Morais, \& Kolinsky, 2015). In particular, previous research has established that learning to read improves children's performance on reading-related phonological tasks, including phoneme awareness (PA), and nonword repetition as well as rapid automatized naming (Peterson et al., 2017). These findings imply that the association between literacy and phonological skills is moderated by development. Consequently, also the findings of structurally (e.g., less gray matter volume) and functionally (e.g., less activated cortical and 
sub-cortical areas) different reading circuits in DD may represent the consequence of a reduced reading development (e.g., Krafnick, Flowers, Luetje, Napoliello, \& Eden, 2014).

Longitudinal studies suggested a causal link between impaired phonological awareness and reading difficulties (see Peterson \& Pennington, 2015, for a review).However, there is a lack of longitudinal studies investigating phonological skills in DD that have controlled for existing literacy skills and grapheme-to-phoneme mapping in their participants (Castles \& Coltheart, 2004). Moreover, it has been shown that specific phonological awareness training does not always automatically transfer to better reading skills (e.g., Galuschka, Ise, Krick, \& Schulte-Körne, 2014;but see Ball \& Blachman, 1988; Bradley \& Bryant, 1983; Moats, 1994, for positive effects of the phonological awareness training on reading remediation in children with DD). It is important to note that recent studies suggest that also other neurocognitive deficits might cause DD (Valdois, Bosse, \& Tainturier, 2004; e.g., Boets, Vandermosten, Cornelissen, Wouters, \&Ghesquière, 2011; Franceschini, Bertoni, Gianesini, Gori, \& Facoetti, 2017; Franceschini, Gori, Ruffino, Pedrolli, \& Facoetti, 2012; Franceschini, Trevisan et al., 2017; Franceschini et al., 2013, 2015; Gori, Bertoni, et al., 2016; Gori et al. 2015; Gori, Molteni, \& Facoetti, 2016; Gori, Seitz, , Franceschini, \& Facoetti, 2016; Kevan \& Pammer, 2009).

Indeed, it can be assumed that DD is a multi-componential and probabilistic, rather than uni-causal and deterministic, neurodevelopmental disorder of learning to read (e.g., Carroll, Solity, \& Shapiro, 2016; Franceschini et al., 2012).As a case in point, alongitudinalstudy by Clark and colleagues (2014) showed that the primary neuroanatomical abnormalities that precede DD are in lower-level areas responsible for visual and auditory processing, and frontal-attentional functions. These findings suggest that dysfunctions in the reading network (e.g., Pugh et al., 2000) may be also a consequence of different reading experiences anddeficits. Although Langer and colleagues (2017) showed abnormalities in the 
white matters inthe areas related to speech in children at risk for DD, explaining DD with a single causeseems to be an unsuccessful approach. It will be argued that at least one cause of DD should to be searched in visual perceptual and attentional deficits.

\section{Research Evidence}

Visual attention deficit is now considered a cause of DD, independently from the auditory-phonological abilities (e.g., Franceschini et al., 2012, 2013, 2015; Gabrieli \& Norton, 2012; Gori, Seitz, et al., 2016). The visual-orthographic system receives attention orienting influence that modulates all visual processing levels (for reviews see Corbetta\& Shulman, 2002, 2011; Facoetti, 2012; Vidyasagar \& Pammer, 2010) from the primary visual cortex (V1) to the visual word form area. This specific region of the fusiform gyrus is involved in identifying words and letters from the visual input, preceding the association with phonology or semantics (Dehaene et al., 2015).During word decoding, attentional orienting isconsidered the resultant of the engagement mechanism onto a letter or grapheme -which has to be mapped to its corresponding speech sound - and the subsequent disengagement mechanism (see Vidyasagar \&Pammer, 2010, for a review). It is important to note that engagement and disengagement mechanisms of visuo-attention orienting act before the linguistic sub-lexical and lexical conversion routes, making the efficient functioning of these mechanisms crucial for reading acquisition independently from writing systems with varying degrees of consistency in letter-to-speech sound relationships.

A visual attentional orienting deficit has been systematically found in DD, irrespective of the transparency of the alphabetic writing system (for reviews see Facoetti, 2004, 2012; Franceschini, Trevisan, et al., 2017; Gori \& Facoetti, 2014, 2015; Gori, Seitz, Ronconi, Franceschini, \& Facoetti, 2016; Hari \& Renvall, 2001; Stein, 2014; Valdois et al., 2004; Vidyasagar \& Pammer, 2010), and more specifically in individuals with DD 
characterized by poor phonological decoding skills (e.g., Cestnick\& Coltheart, 1999;

Facoetti, Trussardi, et al., 2010; Facoetti et al., 2006; Roach \&Hogben, 2007; Ruffino, Gori, Boccardi, Molteni, \& Facoetti, 2014; Ruffino et al., 2010). Interestingly, Liu, Chen, and Chung (2015) found that attentional abilities - independently from phonology and orthography_predict reading skills also in morpheme-based orthgraphies, such as Chinese.

Evidence on the role of visual attention in decoding also comes from atraining study by Franceschini et al. (2013). They showed an effect of an action video game (AVG) training on the spotlight of attention in children with DD in the visual attention span task (Bosse, Tainturier, \&Valdois,2007), where participants had to discriminate one of six visual stimuli. The training with AVG, compared to a non action video game (NAVG) training, lead children with DD to improve their abilities in stimulus discrimination both in a condition of zoom-out (large) and zoom-in (small) attention spotlight (Franceschini et al., 2013). It can be argued that the zoom-in attention spotlight is crucial in shallow languages (e.g., Italian) because the reading unit is primarily the single or the couple of letters, while the zoom-out attention spotlight is necessary to read larger group of letters that are at the basis of reading in opaque languages (e.g., English; Franceschini, Trevisan et al., 2017). Consequently, independently of the consistency between orthography and phonology, a training with AVG could make the weaker attention spotlight of individuals with DD more efficient (e.g.,

Moores, Tsouknida, \& Romani, 2015).

It is important to note that word reading in individuals with DD may be slowed down because of greater crowding effects, which is in agreement to the peculiar spatial distribution of attention (Martelli, Di Filippo, Spinelli, Zoccolotti, 2009; Zorzi et al., 2012; see Gori \& Facoetti, 2015, for a review). Visual crowding occurs when an object becomes more difficult to be identified when surrounded by other objects than when it is in isolation (see Whitney \& Levi, 2011, for a review). Recognition is impaired when objects are closer than a 
criticalspacing (e.g., Yu, Cheung, Legge, \& Chung, 2007), which is the distance between objects at which target recognition is restored (Martelli et al., 2009). Crowding might thus be the resultof a limit in the resolution of spatial attention (e.g., He, Cavanagh, \&Intriligator, 1996; Petrov \& Meleshkevich, 2011; see Gori \& Facoetti, 2015, for a review).

The extra-large spacing between letters and words is able to reduce crowding. Zorzi et al. (2012) showed that a simple manipulation of letter spacing improved text reading performance on the fly (without any training) in a large, unselected sample of Italian and French children with DD. French is a much more opaque language than Italian. In contrast, younger controls matched on reading level (RL) did not show any improvement with the extra-large spacing. This result is congruent with the previous study in Italian children by Spinelli, De Luca, Judica, and Zoccolotti (2002) in which a moderate increase of the spacing between letters improved reading only in individuals with DD. Perea, Panaderó, Moret-Tatay, and Góméz (2012) demonstrated that slight increases in inter-letter spacing improved the readability of texts aimed at Spanish children, especially those with DD. Recently, Schneps and colleagues (Schneps, Thomson, Chen, Sonnert, \& Pomplun, 2013; Schneps, Thomson, Sonnert, et al., 2013) showed that reducing crowding by presenting less words in a line on a small screen improved reading abilities in English speaking individuals with DD. This reading improvement is interpreted as a consequence of the reduced amount of attention necessary to perform the tasks (Schneps, Thomson, Chen,et al., 2013; Schneps, Thomson, Sonnert, et al., 2013; Zorzi et al., 2012). Difficulties for both, words and symbols, indicate that the crowding effect takes place before the process of letter-to-speech sound integration (Moores et al., 2015; Spinelli et al., 2002).

Importantly, there is also evidence thattemporal orienting of attention in the so-called attentional blink task may resultin impairments for individuals with DD (Stein, 2014). The attentional blink task (Raymond, Shapiro, \& Arnell, 1992) consists of two targets shown 
inrapid sequence among distractors. This task evaluates the temporal attention disengagement abilities. Longer recovery times in individuals with DD and in children with specific language impairment (SLI) was found relative to controls in disengaging attention from the first target (Facoetti, Ruffino, Peru, Paganoni, \& Chelazzi, 2008; Hari, Renvall, \&Tanskanen, 2001; Laasonen et al., 2012; Lum, Conti-Ramsden, \& Lindell, 2007;see Badcock \& Kidd, 2015, for a recent review). Individuals with DD and SLI show also poorer performance in the temporal attention engagement on the target when it is rapidly followed by a second object (i.e., backward masking; Di Lollo, Hanson, \& McIntyre, 1983; Dispaldro et al., 2013; Facoetti et al., 2008; Ruffino et al., 2010, 2014). This temporal attention engagement deficit was recently demonstrated to be causally linked to DD by using perceptual learning training (Gori, Seitz, et al., 2016) that improved reading abilities together with temporal attention performance.

Individuals with DD suffer from a deficit of rapid attentional orienting, affecting not only unisensory but also cross-sensory attention (e.g., Virsu, Lahti-Nuuttila \& Laasonen, 2003). Auditory processing deficits are characterizing DD (Tallal, 2004). Children with SLI and DD show difficulties in perceiving speech-sound when it is presented in background noise (e.g., Boets et al., 2011; Geiger et al., 2008; Ziegler, Pech-Georgel, George, Alario, \& Lorenzi, 2005). Rapid auditory processing in infants and toddlers can predict the future language acquisition skills (Benasich \& Tallal, 2002). These disorders in auditory perceptual noise-exclusion could be caused byan attentional deficit (Facoetti, Lorusso, Cattaneo, Galli, \&Molteni, 2005; Facoetti et al., 2003,Facoetti, Trussardi, et al., 2010; Renvall\& Hari, 2002). The temporo-parietal phonological system is influenced by auditory attention which modulates the primary auditory cortex up to the left perisylvian language network (Boets, de Beeck et al., 2013; Dehaene et al., 2015). 
Contrary to what was recently affirmed by Goswami (2015) about the lack of causal studies connecting visual attentional deficit to DD, longitudinal studies and studies with prereading children at risk for DD have shown that visual attention orienting is one of the most important predictors of early reading abilities (e.g., Carroll et al., 2016; Facoetti, Corradi, Ruffino, Gori, \& Zorzi, 2010; Franceschini et al., 2012). In addition, the relationship between attentional skills in pre-reading children and their future reading abilities have been found to be fully independent of phonological processing (Franceschini et al., 2012; Gori, Seitz, et al., 2016). These results clearly rule out the possible explanation suggested by Goswami (2015) about a supposed major role of the reading experience in explaining the attentional deficit found in children with DD. It is important to remind that these studies involved samples that were composed of children with DD but without ADHD. In conclusion, it is proposed that one of the core cognitive deficit underlying DD is the fundamental multimodal spatial and temporal attention orienting mechanisms (which affects both visual and auditory perception) that mediates efficient orthographic-phonological binding (Gori \& Facoetti, 2014, 2015; Hari \& Renvall, 2001), suggesting that attention could also influence the typical auditoryphonological deficits associated to DD (e.g., Facoetti, Trussardi, et al., 2010; Franceschini, Trevisan, et al., 2017).

\section{Explanatory Mechanisms}

A possible neurobiological substrate of temporal and spatial attention orienting deficits in DD could be a weakened magnocellular-dorsal (M-D) stream, and a consequent dysfunction of the main fronto-parietal attentional network (Facoetti, 2012; Livingstone, Rosen, Drislane, \& Galaburda, 1991; Stein \& Walsh, 1997). Although Wright, Conlon and Dyck (2012) suggested that in DD the weaker M sensitivity and visual spatial attention deficits may be independent, impaired attentional orienting system (Boden \&Giaschi, 2007; Hari \& Renvall, 2001; Vidyasagar \& Pammer, 2010) is anatomically contained in the M-D 
stream. Accordingly, several neurophysiological and neuroimaging studies of both typical and atypical reading development (e.g., Cao et al., 2013; Takashima et al., 2014; Turkeltaub, Gareau, Flowers, Zeffiro, \& Eden, 2003; see for review Richlan, 2012) have consistently implicated M-D areas that are known to be part of the visual attention orienting system (Corbetta \& Shulman, 2011). The visual word form area is functionally connected with the dorsal fronto-parietal attention network in the inferior parietal lobule (Vogel, Miezin, Petersen, \& Schlaggar, 2012). Vidyasagar (1999) proposed that an attentional deficitstrongly related to an M-D deficit—could be the main cause of DD (Vidyasagar \&Pammer, 2010).

The theory about a mild M-D deficit at the basis of DD stemmed from the observation that the vast majority of reading disabled children are impaired specifically in the visual M-D pathway (Boden \& Giaschi, 2007; Gori \& Facoetti, 2014, 2015; Stein, 2014; Stein \& Walsh, 1997; Vidyasagar \& Pammer, 2010). The M-D deficit theory is a dominant, albeitcontroversial account (e.g., Olulade, Napoliello, \& Eden, 2013).The M-D pathway originates in the ganglion cells of the retina, passes through the M-layer of the LGN, and finally reaches the occipital and parietal cortices (Maunsell \& Newsome, 1987). This pathway consists of large heavily myelinated neurons with fast conduction velocity (Pammer, 2014). The M-D stream is blind to colors, and responds optimally to contrast differences, low spatial frequencies, high temporal frequencies and both real and illusory motion (e.g.,

Agrillo, C., Gori, S., \& Beran, 2015; Gori, Agrillo, et al., 2014; Gori, Giora, \& Stubbs, 2010; Gori, Giora, Yazdanbakhsh, \& Mingolla, 2011; Gori \& Hamburger, 2006; Gori \& Yazdanbakhsh 2008; Livingstone \& Hubel, 1987; Morrone et al., 2000; Ruzzoli et al., 2011; Yazdanbakhsh \& Gori, 2011).Much of the evidence supporting the M-D deficit theory of DD is related toresearch on perception of coherent dot motion (CDM, e.g., Boets et al., 2011; 
Cornelissen, Richardson, Mason, Fowler, \& Stein, 1995), which heavily relies upon processing within the M-D pathway (Newsome \& Pare, 1998).

Consistent with the M-D deficit theory of DD, individuals with DD and pre-readers at risk for DD show poor performance on CDM tasks compared to typically reading controls (Boets et al., 2011; Eden et al., 1996; Gori, Seitz, et al., 2016; Kevan \& Pammer, 2008), while performing similarly to the controls on tasks mainly associated with the parvocellularventral pathway (Gori, Cecchini, Bigoni, Molteni, \& Facoetti, 2014, Gori et al, 2015; Kevan \& Pammer, 2009). It has been reported that up to $75 \%$ of dyslexic individuals showvisual MD processing deficits (Lovegrove, Martin, \& Slaghuis, 1986). Moreover, a post mortem study showed that M-neurons of the LGN were significantly smaller in individuals with DD than those of normal readers. On the contrary, the Parvocellular-neurons did not differ between the two groups (Livingstone et al., 1991). These findings were confirmed byin vivo MRI study (Giraldo-Chica, Hegarty, \& Schneider, 2015). Recently, Gori et al. (2015) demonstrated that children with DD showed lower performance in tasks related to visual illusions that rely upon the M-D pathway (i.e., the spatial frequency doubling illusion; Kelly, 1966, the rotating tilted lines illusion, and the accordion grating illusion, Gori et al., 2010; 2011; Gori, Giora, Yazdanbakhsh, \& Mingolla, 2013; Gori \& Hamburger 2006; Gori \&Yazdanbakhsh, 2008; Yazdanbakhsh\& Gori, 2011) in comparison with both to age matched and RL controls. Gori et al. (2015) also reported the first association between a genetic variance (the DCDC2-Intron 2 deletion) and M-D deficits in both individuals with DD and typical readers. Interestingly the M-D deficit in individuals with DD was found also in logographic languages such as Chinese (e.g., Zhao, Qian, Bi, \& Coltheart, 2014).

While there exists a substantial body of evidence suggesting a relationship between M-D processing and DD (Stein, 2014), the main criticism of this theory was that M-D deficits may not be causal to DD and, instead, could be a consequence of lack of reading experience 
(Goswami, 2015; Oluladeet al., 2013) since children with DD read far less than their peers(e.g., Cunningham \& Stanovich, 1997). Recently, Gori, Seitz, and colleagues (2016) showed that: (i) motion perception was impaired in children with DD in comparison both to age-match and to RL controls; (ii) pre-reading visual motion perception-independently from auditory-phonological skill—-predicted future reading development; (iii) targeted M-D trainings — not involving any phonological stimulation—lead to improved reading skill in children and adults with DD; and (iv) in a parvocellular-ventraltask involving noise exclusion no difference in the DD group was found. These findings demonstrate, for the first time, a causal relationship between M-D deficits and DD,although it should be noted that this study was conducted on unselected samples. However, notwithstanding the heterogenic nature of the cognitive profiles on DD, the M-D deficit seems to be so basic that it may have a cascade effect on the other cognitive functions.

\section{Clinical Implications}

Evidence shows that there is no word identification without spatial attention orienting (e.g., Robidoux, Rauwerda, \& Besner, 2014). Specific intervention studies led to both,auditory and visual orienting of attention improvements in children with DD (e.g., Facoetti et al., 2003; Franceschini, Trevisan et al., 2017; Franceschini et al., 2013; Geiger, Lettvin, \&Fahle, 1994). These studies demonstrated that the inhibitory mechanism of attentional orienting — which is crucial for perceptual noise exclusion—can be remediated with appropriate rehabilitation programs. Computer games have proven to be efficient in improving auditory temporal processing and spatial attention in children with SLI (Stevens, Fanning, Donna, Sanders, \& Neville, 2008; Tallal et al., 1996; see Tallal, 2004, for a review).

There is evidence that playing action video gamesalso significantly improves visual and auditory attentional orienting (Green \& Bavelier, 2003; Green, Pouget\& Bavelier, 
2010).AVG training generalizes to various tasks beyond game situations, allowing gamers to better allocate their attention across both space and time. AVGs share an extraordinary speed in terms of transient events and moving objects, a high degree of perceptual and motor load, and an emphasis on peripheral processing. All of these visual characteristics are processed by the M-D stream, consequently the AVG treatment could be mainly tapping into the M-D pathway (Franceschini et al., 2013; Gori \& Facoetti 2014; Gori, Seitz, et al., 2016). In a study by Franceschini et al. (2013), it was demonstrated, for the first time, that AVG training makes children with DD read better. These authors measured the phonological decoding of pseudowords and word text reading skills in children with DD before and after two video game trainings (AVG or non-action videogame player NAVG). After 12 hours of treatment (9 days in total) the AVG training players improved in basic phonological decoding and in lexical recognition measured by the word text reading. Results, in syllables per seconds, showed that children treated with AVG training had an improvement higher what is expected in a child with DD after one year of schooling, and bigger or equal than those obtained by the highly demanding traditional DD training (Franceschini et al., 2013). Individual analysis showed that $80 \%$ of AVG players statistically differed from the NAVG group. After the AVG training, attentional and reading improvements were highly correlated even after controlling for phonological training-induced changes, showing how unfounded the phonological interpretation of these results recently suggested by Goswami (2015) was. These results have been confirmed in a second study (Gori, Seitz, et al., 2016), in which a group of children with DD was trained using NAVG before and AVG after in a withinsubject design. The NAVG training led to no significant effects. On the contrary, training with AVG showed large improvements in words and pseudowords text reading, stressing the importance of using AVG as a possible training in DD. These results were further confirmedalso when children with DD were in comorbidity with dyscalculia (Gori, Tait, et 
al., 2014). Inthese AVG training studies (Franceschini et al., 2013; Gori, Seitz, et al., 2016;

Gori, Tait, et al., 2014) no drop-out was observed.

Although the association between a mild M-D deficit and DD has been consistently observed (see Boden \& Giaschi, 2007; Gori \& Facoetti, 2014, 2015; Hari \& Renvall, 2001; Laycock \& Crewther, 2008; Schulte-Körne \& Bruder, 2010; Stein, 2012, 2014; Stein \& Walsh, 1997; Vidyasagar, 1999; Vidyasagar \& Pammer, 2010; Walsh, 1995, for reviews), the lack of studies employing training designs led to debate regarding the relationship between M-D pathway deficits and reading disorders (Goswami, 2015). Interestingly, Gori, Seitz, and colleagues (2016) showed that not only reading skills, but also M-D pathway functionality was specifically improved after the AVG training in children with DD, whereas parvocellular-ventral performances were unaffected. The specific effect of AVG training on the M-D pathway is confirmed also by improved illusory motion perception which is an accepted proxy of the M-D functionality that is not related to perceptual noise exclusion (Gori, Seitz, et al., 2016). These results not only expand on previous findings, but also indicate that the underlying neural substrate of the AVG training appears to be the M-D pathway.

The AVG training presents important advantages to the development of specific training modules for $\mathrm{DD}$, because of the appealing task that encourages compliance. However, the complex tasks involved in commercial video games make it difficult to isolate the core mechanisms of how this type of training impacts DD. Consequently, a training that is specifically based on the M-D pathway is necessary to further establish the causal role of the M-D deficit in DD.In the same study, Gori, Seitz, and colleagues (2016) showed that a directtraining of the M-D pathway based on a coherent dot motion perceptual learning procedure drastically improved the reading skills in adults with DD. Improvements in the MD pathway functioning directly translated to better reading skills. Specific M-D pathway 
training also increased both peripheral visual perception and temporal mechanism of visual attention orienting, confirming the suggested link between M-D pathway functioning and attentional mechanisms. Moreover, the training-induced perceptual and attentional changes explained a large quote of variance of the reading performance gain of the individuals with DD, demonstrating the causal link between M-D pathway and reading skills (see also Lawton, 2016).

Furthermore, Gori, Seitz, and colleagues (2016) found significant improvement in auditory-phonological abilities after AVG treatment, showing that M-D functioning and attentional training can also affect phonological skills (see also Lawton, 2016). These findings confirm the cross- and multisensory effects of the AVG training (e.g., Franceschini trevisan et al., 2017; Franceschini et al., 2013; Green et al., 2010). Indeed, Green et al. (2010) demonstrated that AVG can improve a range of spatial and temporal aspects of visual and auditory attention, not strictly connected to the ones directly trained by the video game use per se. The authors also showed that a better use of sensory evidence (or target filtering) could be obtained by AVG players in tasks that involved not only visual, but also auditory stimuli (see Bavelier, Green, Pouget, \& Schrater, 2012; Dye, Green, \& Bavelier, 2009; Green \& Bavelier, 2012, for reviews on "learn to learn" effects of AVGs). Consistently, there is evidence in support of the M-D temporal hypothesis explicitly claiming that phonological decoding deficits in individuals with DD could arise from impairments in sensory processing of visual and auditory dynamic-stimuli (e.g.,Facoetti, Trussardi, et al., 2010; Lallier,

Tainturier et al., 2010; Vidyasagar, 2013; Witton et al., 1998).

It is important to note that the studies by Franceschini et al. (2013), Gori, Cecchini, et al., (2014), Gori, Seitz, et al. (2016) were based on Italian, a transparent orthography in comparison to other languages, such as English. One may argue that these results could not be easily generalized to other opaque languages, such as English, because of the high level of 
transparency characterizing Italian. In transparent orthographies it is possible that phonological deficits may be less relevant for DD than more opaque ones. However, difference in orthographic transparency seems not crucial. Indeed, there is evidence that both word recognition and phonological decoding were significantly and clinically improved also in English speaking children with DD (Franceschini, Trevisan, et al., 2017). In this recent study, auditory-phonological working memory, as well as visual-to-auditory attention orienting,were significantly improved, confirming a direct role of multi-sensory and crossmodal attention orienting mechanisms in reading remediation also in more opaque orthographies. It could be supposed that the perceptual and the attentional mechanisms controlled by the M-D pathway precede the orthographic-to-phonological mapping (e.g., Pammer, Hansen, Holliday, \& Cornelissen, 2006; Zorzi et al., 2012). The attentional and MD deficits are peripheral by definition. The DD characterized by peripheral deficits is often found irrespectively of different degrees of orthographic transparency (Zorzi et al., 2012). Thus, it is likely that attentional and M-D trainings will be beneficial to individuals with DD regardless the DD subtypes and the deepness of the language.

To date, DD prevention is only a dream far from being achieved (Gabrieli, 2009). However, Gori, Bertoni, and colleagues (2016) showed that only 20 hours of playing AVGnot involving any direct phonological or orthographic training - improved early visual and auditory predictors of future reading abilities in pre-reading children at risk of DD. Gori, Bertoni, and colleagues (2016) tested rapid naming, letter knowledge, auditory-phonological skills and visuo-attentional spotlight efficiency (i.e., earliest predictors of reading acquisition) in three matched groups of prereading children at cognitive risk of DD before and after they played AVG, NAVG or no-treatment for 20 sessions of 60 minutes per day. It was found that only playing AVG improved pre-reading children visual and phonological predictors of future reading abilities. These results show, that attention orienting improvements can

Formattato: Tipo di carattere: $12 \mathrm{pt}$, Colore carattere: Automatico, (asiatico) Cinese (Repubblica popolare cinese), (Altro) Inglese (Stati Uniti), Non Evidenziato 
directly translate into better language abilities in prereading children at risk for DD, providing a new, fast, and fun prevention training for DD.

\section{Conclusions}

In sum, several findings, consistently across methods and languages, demonstrate a causal role of visual attention and M-D pathway deficits in DD. It can thus be assumed that the unsuccessful search for a single cause for DD, makes the identification of other causes than phonological awareness of utmost importance. Attentional and M-D pathway training were found to be crucial methods to remediate DD independently of auditory-phonological approaches. Inside a multi-factorial and probabilistic hypothesis for DD (Menghini et al., 2010), the attentional and M-D pathway training seems to be a very promising future practice that should be added to the more traditional approaches for DD remediation. The most intriguing aspect of these visual trainings is the possibility to obtain generalization to the visual aspect of reading, also using stimuli far from strings of letters, often at the basis of more traditional language and phonological decoding training modules. A combination of these kinds of treatment may further reduce the drop-out and improve the reading remediationin children with DD.The fact that both visual attentional and M-D pathway deficits can be tested and training during infancy paves the way for more effective DD remediation and prevention programs. 


\section{References}

Agrillo, C., Gori, S., \&Beran, M.J. (2015). Do rhesus monkeys (Macacamulatta) perceive illusory motion? Animal Cognition, 18, 895-910. doi:10.1007/s10071-015-0860-6

Badcock, N.A., \& Kidd, J.C. (2015). Temporal variability predicts the magnitude of betweengroup attentional blink differences in developmental dyslexia: A meta-analysis. PeerJ, 3(e746), 1-18. doi:10.7717/peerj.746

Ball, E. W., \&Blachman, B. A. (1988). Phoneme segmentation training: Effect on reading readiness. Annals of Dyslexia, 38, 208-225.

Battelli, L., Pascual-Leone, A., \& Cavanagh, P. (2007). The "when" pathway of the right parietal lobe. Trends in Cognitive Sciences, 11, 204-210. doi:10.1016/j.tics.2007.03.001

Bavelier, D., Green, C. S., Pouget, A., \&Schrater, P. (2012). Brain plasticity through the life span: Learning to learn and action video games. Annual Review of Neurosciences, 35 , $391-416$.

Benasich, A.A., \&Tallal, P. (2002). Infant discrimination of rapid auditory cues predicts later language impairment. Behavioural Brain Research, 136, 31-49.

Boden, C., \&Giaschi, D. (2007). M-stream deficits and reading-related visual processes in developmental dyslexia. Psychological Bulletin, 133, 346-366. doi:10.1037/00332909.133.2.346

Boets, B., de Beeck, H. P. O., Vandermosten, M., Scott, S. K., Gillebert, C. R., Mantini, D., ... \& Ghesquière, P. (2013). Intact but less accessible phonetic representations in adults with dyslexia. Science, 342(6163), 1251-1254.

Formattato: Tipo di carattere: 12 pt, Non Corsivo, Inglese (Stati Uniti) 
Boets, B., Vandermosten, M., Cornelissen, P., Wouters, J., \&Ghesquière, P. (2011). Coherent motion sensitivity and reading development in the transition from pre-reading to reading stage. Child Development, 82, 854-869. doi:10.1111/j.14678624.2010.01527.x

Bosse, M. L., Tainturier, M. J., \&Valdois, S. (2007). Developmental dyslexia: The visual attention span deficit hypothesis. Cognition, 104, 198-230. doi:10.1016/j.cognition.2006.05.009

Bradley, L., \& Bryant, P. E. (1983). Categorizing sounds and learning to read-a causal connection. Nature, 301, 419-421.

Cao, F., Rickles, B., Vu, M., Zhu, Z., Chan, D.H., Harris, L.N., ... Perfetti, C.A. (2013). Early stage visual-orthographic processes predict long-term retention of word form and meaning: A visual encoding training study. Journal of Neurolinguistics, 26, 440461.

Carrasco, M. (2011). Visual attention: The past 25 years. Vision Research, 51, 1484-1525. doi:10.1016/j.visres.2011.04.012

Carroll, J.M., Solity, J., \& Shapiro, L.R. (2016). Predicting dyslexia using prereading skills: The role of sensorimotor and cognitive abilities. Journal of Child Psychology and Psychiatry, 57, 750-758.

Castles, A., \& Coltheart, M. (2004). Is there a causal link from phonological awareness to success in learning to read? Cognition, 91, 77-111. doi:10.1016/S00100277(03)00164-1

Cestnick, L., \& Coltheart, M. (1999). The relationship between language-processing and visual-processing deficits in developmental dyslexia. Cognition, 71, 231-255. doi:10.1016/S0010-0277(99)00023-2 
Clark, K.A., Helland, T., Specht, K., Narr, K.L., Manis, F.R., Toga, A.W., \&Hugdahl, K. (2014). Neuroanatomical precursors of dyslexia identified from pre-reading through to age 11. Brain,137, 3136-3141. doi:10.1093/brain/awu229

Corbetta, M., \& Shulman, G.L. (2002). Control of goal-directed and stimulus-driven attention in the brain. Nature Review Neuroscience, 3, 201-215. doi:10.1038/nrn755

Corbetta, M., \& Shulman, G.L. (2011). Spatial neglect and attention networks. Annual Review of Neuroscience, 34, 569-599. doi:10.1146/annurev-neuro-061010-113731

Cornelissen, P., Richardson, A., Mason, A., Fowler, S., \& Stein, J. (1995). Contrast sensitivity and coherent motion detection measured at photopic luminance levels in dyslexics and controls. Vision Research, 35, 1483-1494.

Cunningham, A.E., \& Stanovich, K.E. (1997). Early reading acquisition and its relation to reading experience and ability 10 years later. Developmental Psychology, 33, 934945.

Dehaene, S., Cohen, L., Morais, J., \& Kolinsky, R. (2015). Illiterate to literate: Behaviouraland cerebral changes induced by reading acquisition. Nature Review Neuroscience, 16, 234-244. doi:10.1038/nrn3924

Di Lollo, V., Hanson, D., \& McIntyre, J. S. (1983). Initial stages of visual information processing in dyslexia. Journal of Experimental Psychology: Human Perception \& Performance, 9, 923-935. doi:10.1037/0096-1523.9.6.923

Dispaldro, M., Leonard, L.B., Corradi, N., Ruffino, M., Bronte, T., \&Facoetti, A. (2013). Visual attentional engagement deficits in children with Specific Language Impairment and their role in real-time language processing. Cortex, 49, 21262139.doi:10.1016/j.cortex.2012.09.012

Dye, M.W., Green, C.S., \& Bavelier, D. (2009). Increasing speed of processing with action video games. Current Direction in Psychology Science, 18, 321-326. 
Eden, G.F., VanMeter, J. W., Rumsey, J. M., Maisog, J.M., Woods, R. P., \&Zeffiro, T.A. (1996). Abnormal processing of visual motion in dyslexia revealed by functional brain imaging. Nature, 382, 66-69. doi:10.1038/382066a0

Facoetti, A. (2004). Reading and selective spatial attention: Evidence from behavioral studies in dyslexic children. In H.D. Tobias (Ed.),Trends in dyslexia research(pp. 35-71). New York, NY: Nova Biomedical Books.

Facoetti, A. (2012). Spatial attention disorders in developmental dyslexia: Towards the prevention of reading acquisition deficits. In J. Stein \& Z. Kapoula (Eds.), Visual aspects of dyslexia (pp. 123-136). Oxford, UK: Oxford University Press. doi:10.1093/acprof:oso/9780199589814.003.0008

Facoetti, A., Corradi, N., Ruffino, M., Gori, S., \&Zorzi, M. (2010). Visual spatial attention and speech segmentation are both impaired in preschoolers at familial risk for developmental dyslexia. Dyslexia, 16, 226-239. doi:10.1002/dys.413

Facoetti, A., Lorusso, M. L., Cattaneo, C., Galli, R., \&Molteni, M. (2005). Visual and auditory attentional capture are both sluggish in children with developmental dyslexia. Acta NeurobiologiaeExperimentalis, 65, 61-72.

Facoetti, A., Lorusso, M. L., Paganoni, P., Umiltà, C., \&Mascetti, G.G. (2003). The role of visuospatial attention in developmental dyslexia: Evidence from a rehabilitation study. Cognitive Brain Research, 15, 154-164. doi:10.1016/S0926-6410(02)00148-9

Facoetti, A., \&Molteni, M. (2000). Is attentional focusing an inhibitory process at distractor location? Cognitive Brain Research, 10, 185-188. doi:10.1016/S09266410(00)00031-8

Facoetti, A., Paganoni, P., Turatto, M., Marzola, V., \&Mascetti, G.G. (2000). Visual-spatial attention in developmental dyslexia. Cortex, 36, 109-123. 
Facoetti, A., Ruffino, M., Peru, A., Paganoni, P., \&Chelazzi, L. (2008). Sluggish engagement and disengagement of non-spatial attention in dyslexic children. Cortex, 44, 12211233. doi:10.1016/j.cortex.2007.10.007

Facoetti, A., Trussardi, A.N., Ruffino, M., Lorusso, M.L., Cattaneo, C., Galli, R., ... Zorzi, M. (2010). Multisensory spatial attention deficits are predictive of phonological decoding skills in developmental dyslexia. Journal of Cognitive Neuroscience, 22, 1011-1025. doi:10.1162/jocn.2009.21232

Facoetti, A., Zorzi, M., Cestnick, L., Lorusso, M.L., Molteni, M., Paganoni, P., ... Mascetti,G. G. (2006). The relationship between visuo-spatial attention and nonword reading in developmental dyslexia. Cognitive Neuropsychology, 23, 841-855. doi:10.1080/02643290500483090.

Franceschini, S., Bertoni, S., Gianesini, T., Gori, S., \&Facoetti, A. (2017). A different vision of dyslexia: Local precedence on global perception. Scientific Reports,7,17462. doi:10.1038/s41598-017-17626-1

Franceschini, S., Bertoni, S., Ronconi, L., Molteni, M., Gori, S., \& Facoetti, A. (2015). "Shall we play a game?": Improving reading through action video games in developmental dyslexia. Current Developmental Disorders Reports, 2, 318-329. doi:10.1007/s40474-015-0064-4

Franceschini, S., Gori, S., Ruffino, M., Pedrolli, K., \& Facoetti, A. (2012). A causal link between visual spatial attention and reading acquisition. Current Biology, 22(9), 814_819. doi:10.1016/j.cub.2012.03.013.

Franceschini, S., Gori, S., Ruffino, M., Viola, S., Molteni, M., \& Facoetti, A. (2013). Action video games make dyslexic children read better. Current Biology, 23, 462-466. doi:10.1016/j.cub.2013.01.044 
Franceschini, S., Trevisan, P., Ronconi, L., Bertoni, S., Colmar, S., Double, K., ... \& Gori, S. (2017). Action video games improve reading abilities and visual-to-auditory attentional shifting in English-speaking children with dyslexia. Scientific Reports, 7, 5863.

Gabrieli, J.D. (2009). Dyslexia: A new synergy between education and cognitive neuroscience. Science, 325, 280-283. doi:10.1126/science.1171999

Gabrieli, J.D., \& Norton, E.S. (2012). Reading abilities: Importance of visual-spatial attention. Current Biology, 22, R298-R299. doi:10.1016/j.cub.2012.03.041

Galuschka, K., Ise, E., Krick, K., \& Schulte-Körne, G. (2014). Effectiveness of treatment approaches for children and adolescents with reading disabilities: A meta-analysis of randomized controlled trials. PLoS ONE, 9(2), e89900. doi:10.1371/journal.pone.0089900

Geiger, G., Cattaneo, C., Galli, R., Pozzoli, U., Lorusso, M.L., Facoetti, A., \&Molteni, M. (2008). Wide and diffuse perceptual modes characterize dyslexics in vision and audition. Perception, 37, 1745-1764.

Geiger, G., Lettvin, J.Y., \&Fahle, M. (1994). Dyslexic children learn a new visual strategy for reading: A controlled experiment. Vision Research, 34, 1223-1233. doi:10.1016/0042-6989(94)90303-4

Giraldo-Chica, M., Hegarty, J.P. 2nd., \& Schneider, K.A. (2015). Morphological differences in the lateral geniculate nucleus associated with dyslexia. Neuroimage Clinical, 7, 830-836.doi:10.1016/j.nicl.2015.03.011

Gori, S., Agrillo, A., Dadda, M., \&Bisazza, A. (2014). Do fish perceive illusory motion? Scientific Reports, 4, 6443. doi:10.1038/srep06443. 
Gori, S., Bertoni, S., Sali, M.E., Ruffino, M., Franceschini, S., Ronconi, L., ... Facoetti, A. (2016). Dyslexia prevention by action video game training: Behaviouraland neurophysiological evidence. Journal of Vision, 16, 489. doi:10.1167/16.12.489

Gori, S., Cecchini, P., Bigoni, A., Molteni, M., \& Facoetti, A. (2014). Magnocellular-dorsal pathway and sub-lexical route in developmental dyslexia. Frontiers in Human Neuroscience, 8,460 . doi:10.3389/fnhum.2014.00460

Gori, S., \& Facoetti, A. (2014). Perceptual learning as a possible new approach for remediation and prevention of developmental dyslexia. Vision Research, 99, 78-87. doi:10.1016/j.visres.2013.11.011

Gori, S., \&Facoetti, A. (2015). How the visual aspects can be crucial in reading acquisition? The intriguing case of crowding and developmental dyslexia. Journal of Vision, 15,8. doi:10.1167/15.1.8

Gori, S., Giora, E., \& Stubbs, D. A. (2010). Perceptual compromise between apparent and veridical motion indices: The Unchained-Dots illusion. Perception, 39(6), 863-_866. doi:10.1068/p6678

Gori, S., Giora, E., Yazdanbakhsh, A., \&Mingolla, E. (2011). A new motion illusion based on competition between two kinds of motion processing units: The Accordion Grating. Neural Networks, 24(10), 1082__1092. doi:10.1016/j.neunet.2011.06.017

Gori, S., Giora, E., Yazdanbakhsh, A., \&Mingolla, E. (2013). The novelty of the ${ }_{-}^{\prime \prime c}$ Accordion Grating Illusion"..".Neural Network,39, 52. doi:10.1016/j.neunet.2012.07.008Formattato: Tipo di carattere: $12 \mathrm{pt}$, Corsivo, Colore carattere: Automatico, Inglese (Stati Uniti)

Gori, S., \& Hamburger, K. (2006). A new motion illusion: The Rotating-Tilted-Lines illusion. Perception, 35, 853-857. doi:10.1068/p5531 
Gori, S., Mascheretti, S., Giora, E., Ronconi, L., Ruffino, M., ... Marino, C. (2015). The $D C D C 2$ intron 2 deletion impairs illusory motion perception unveiling the selective role of magnocellular-dorsal stream in reading (dis)ability. Cerebral Cortex, 25, 1685-1695. doi:10.1093/cercor/bhu234

Gori, S., Molteni, M., \& Facoetti, A. (2016). Visual illusions: An interesting tool to investigate developmental dyslexia and autism spectrum disorder. Frontiers in Human Neuroscience, 10, 175. doi:10.3389/fnhum.2016.00175

Gori, S., Seitz, A. R., Ronconi, L., Franceschini, S., \& Facoetti, A. (2016). Multiple causal links between magnocellular-dorsal pathway deficit and developmental dyslexia. Cerebral Cortex, 26, 4356-4369.

Gori, S., Tait, M., Franceschini, S., Casagrande, E., Robino, C., De’Sperati, C., \& Facoetti, A. (2014, July). Dyscalculia remediation by action video games. Abstract Number: FENS-3332. Poster session presented at Forum of Neuroscience (FENS), Milan, Italy.

Gori, S., \& Yazdanbakhsh, A. (2008). The riddle of the Rotating-Tilted-Lines illusion. Perception, 37, 631-635. doi:10.1068/p5770

Goswami, U. (2015). Sensory theories of developmental dyslexia: Three challenges for research. Nature Reviews Neuroscience, 16, 43-54. doi:10.1038/nrn3836

Green, C.S., \& Bavelier, D. (2003). Action video game modifies visual selective attention. Nature,423, 534-537.

Green, C.S., \& Bavelier, D. (2012). Learning, attentional control and action video games. Current Biology,22, R197-R206. doi:10.1016/j.cub.2012.02.012.

Green, C.S., Pouget, A., \& Bavelier, D. (2010). Improved probabilistic inference as a general learning mechanism with action video games. Current Biology, 20, 1573-1579. doi:10.1016/j.cub.2010.07.040 
Hari, R., \&Renvall, H. (2001). Impaired processing of rapid stimulus sequences in dyslexia. Trends in Cognitive Sciences, 5, 525-532. doi:10.1016/S1364-6613(00)01801-5

Hari, R., Renvall, H., \&Tanskanen, T. (2001). Left minineglect in dyslexic adults. Brain, 124, 1373-1380.

He, S., Cavanagh, P., \&Intriligator, J. (1996). Attentional resolution and the locus of visual awareness. Nature, 383, 334-337. doi:10.1038/383334a0

Kelly, D. (1966). Frequency doubling in visual responses. Journal of the Optical Society ofAmerica, 56, 1628-1633. doi:10.1364/JOSA.56.001628.

Kevan, A., \&Pammer, K. (2008). Visual deficits in pre-readers at familial risk for dyslexia. Vision Research, 48, 2835-2839. doi:10.1016/j.visres.2008.09.022

Kevan, A., \&Pammer, K. (2009). Predicting early reading skills from pre-reading measures of dorsal stream functioning. Neuropsychologia, 47, 3174-3181. doi:10.1016/j.neuropsychologia.2009.07.016

Krafnick, A.J., Flowers, D.L., Luetje, M.M., Napoliello, E.M., \& Eden, G.F. (2014). An investigation into the origin of anatomical differences in dyslexia. Journal of Neuroscience, 34, 901-908. doi:10.1523/JNEUROSCI.2092-13.2013

Laasonen, M., Salomaa, J., Cousineau, D., Leppämäki, S., Tani, P., Hokkanen, L., \& Dye, M. (2012). Project DyAdd: Visual attention in adult dyslexia and ADHD. Brain and cognition, 80, 311-327.

Lallier, M., Tainturier, M. J., Dering, B., Donnadieu, S., Valdois, S., \& Thierry, G. (2010). Behavioral and ERP evidence for amodal sluggish attentional shifting in developmental dyslexia. Neuropsychologia, 48, 4125-4135.

Langer, N., Peysakhovich, B., Zuk, J., Drottar, M., Sliva, D. D., Smith, S., ...Gaab, N. (2017). White matter alterations in infants at risk for developmental dyslexia. Cerebral Cortex, 27, 1027-1036. 
Lawton, T. (2016). Improving dorsal stream function in dyslexics by training figure/ground motion discrimination improves attention, reading fluency, and working memory. Frontiers Human Neuroscience, 10, 397.

Laycock, R., \& Crewther, S.G. (2008). Towards an understanding of the role of the 'magnocellular advantage' in fluent reading. Neuroscience \& Biobehavioral Review, 32, 1494-1506. doi:10.1016/j.neubiorev.2008.06.002

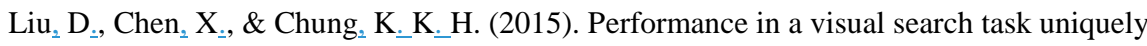
predicts reading abilities in third-grade Hong Kong Chinese children. Scientific Studies of Reading, 19, 307-324.

Livingstone, M. S., \& Hubel, D. H. (1987). Psychophysical evidence for separate channels for the perception of form, color, movement, and depth. Journal of Neuroscience, 7 , 3416-3468.

Livingstone, M. S., Rosen, G. D., Drislane, F. W., \&Galaburda, A. M. (1991). Physiological and anatomical evidence for a magnocellular defect in developmental dyslexia. Proceedings of the National Academy of Sciences of the United States of America, 88, 7943-7947. doi:10.1073/pnas.88.18.7943

Lovegrove, W., Martin, F., \& Slaghuis, W.A. (1986). A theoretical and experimental case forvisualdeficit in specific reading disability. Cognitive Neuropsychology, 3, 225-267.

Lum, J.A., Conti-Ramsden, G., \& Lindell, A.K. (2007). The attentional blink reveals sluggish attentional shifting in adolescents with specific language impairment. Brain and Cognition,63, 287-295.

Martelli, M., Di Filippo, G., Spinelli, D., \&Zoccolotti, P., (2009). Crowding, reading, and developmental dyslexia. Journal of Vision, 9, 14. doi:10.1167/9.4.14

Maunsell, J.H., \& Newsome, W.T. (1987). Visual processing in monkey extrastriate cortex.Annual review of Neuroscience, 10, 363-401. 
Menghini, D., Finzi, A., Benassi, M., Bolzani, R., Facoetti, A., Giovagnoli, S., ... Vicari, S. (2010). Different underlying neurocognitive deficits in developmental dyslexia: A comparative study. Neuropsychologia, 48, 863-872.

doi:10.1016/j.neuropsychologia.2009.11.003

Moats, L. C. (1994). The missing foundation in teacher education: Knowledge of the structure of spoken and written language. Annals of dyslexia, 44, 81-102.

Moores, E., Tsouknida, E., \& Romani, C. (2015). Adults with dyslexia can use cues to orient and constrain attention but have a smaller and weaker attention spotlight. Vision Research, 111, 55-65.

Morrone, M.C., Tosetti, M., Montanaro, D., Fiorentini, A., Cioni, G., \& Burr, D.C. (2000). A cortical area that responds specifically to optic flow, revealed by fMRI. Nature Neuroscience, 3, 1322-1328. doi:10.1038/81860

Newsome, W.T., \& Pare, E.B. (1998). A selective impairment of motion perception following lesions of the middle temporal visual area (MT). Journal of Neuroscience, $8,2201-2211$.

Olulade, O.A., Napoliello, E.M., \& Eden, G.F. (2013). Abnormal visual motion processing is not a cause of dyslexia. Neuron, 79, 180-190. doi:10.1016/j.neuron.2013.05.002

Pammer, K. (2014). Temporal sampling in vision and the implications for dyslexia. Frontiers in human neuroscience,7, 933. doi:10.3389/fnhum.2013.00933

Pammer, K., Hansen, P., Holliday, I., \& Cornelissen, P. (2006). Attentional shifting and the role of the dorsal pathway in visual word recognition. Neuropsychologia, 44, 29262936.

Perea, M., Panaderó, V., Moret-Tatay, C., \&Góméz, P. (2012). The effects of inter-letter spacing in visual-word recognition: Evidence with young normal readers and developmental dyslexics. Learning and Instruction, 22, 420-430. 
Petersen, S.E., \& Posner, M.I. (2012). The attention system of the human brain: 20 years after. Annual Review of Neuroscience, 35, 73-89. doi:10.1146/annurev-neuro062111-150525

Peterson, R. L., Arnett, A. B., Pennington, B. F., Byrne, B., Samuelsson, S., \& Olson, R. K. (2017). Literacy acquisition influences children's rapid automatized naming.Developmental Science. Advance online publication. doi:10.1111/desc.12589

Peterson, R.L.,\& Pennington, B.F. (2015). Developmental dyslexia. Annual review of clinical Psychology,11, 283-307. doi:10.1146/annurev-clinpsy-032814-112842

Petrov, Y., \&Meleshkevich, O. (2011). Locus of spatial attention determines inward-outward anisotropy in crowding. Journal of Vision, 11, 1. doi:10.1167/11.4.1

Pugh, K.R., Mencl, W.E., Shaywitz, B.A., Shaywitz, S.E., Fulbright, R.K., Constable, R. T., ...Gore, J.C. (2000). The angular gyrus in developmental dyslexia: Task-specific differences in functional connectivity within posterior cortex. Psychological Science, 11, 51-56. doi:10.1111/1467-9280.00214

Raymond, J.E., Shapiro, K.L., \& Arnell, K.M. (1992). Temporary suppression of visual processing in an RSVP task: An attentional blink? Journal of Experimental psychology: Human Perception and Performance, 18, 849-860.

Renvall, H., \& Hari, R. (2002). Auditory cortical responses to speech-like stimuli in dyslexic adults.Journal of Cognitive Neuroscience, 14, 757-768.

Richlan, F. (2012). Developmental dyslexia: Dysfunction of a left hemisphere reading network. Frontiersin Human Neuroscience, 6, 120. doi:10.3389/fnhum.2012.00120

Roach, N.V., \&Hogben, J. H. (2007). Impaired filtering of behaviourally irrelevant visual information in dyslexia. Brain, 130, 771-785. doi:10.1093/brain/awl353 
Robidoux, S., Rauwerda, D., \&Besner, D. (2014). Basic processes in reading aloud andcolour naming: Towards a better understanding of the role of spatial attention. The Quarterly Journal of Experimental Psychology, 67, 979-990. doi:10.1080/17470218.2013.838686

Roelfsema, P.R., van Ooyen, A., \& Watanabe, T. (2010). Perceptual learning rules based on reinforcers and attention. Trends in Cognitive Sciences, 14, 64-71. doi:10.1016/j.tics.2009.11.005

Ronconi, L., Basso, D., Gori, S., \& Facoetti, A. (2014). TMS on right frontal eye fields induces an inflexible focus of attention. Cerebral Cortex, 24, 396-402. doi:10.1093/cercor/bhs319

Ronconi, L., Facoetti, A., Bulf, H., Franchin, L., Bettoni, R., \&Valenza, E. (2014). Paternal autistic traits are predictive of infants visual attention. Journal of Autism and Developmental Disorders,44, 1556-1564. doi:10.1007/s10803-013-2018-1

Ronconi, L., Gori, S., Ruffino, M., Molteni, M., \& Facoetti, A. (2013). Zoom-out attentional impairment in children with autism spectrum disorder. Cortex, 49(4), 1025-1033.

Ronconi, L., Pincham, H.L., Szücs, D., \&Facoetti, A. (2016). Inducing attention not to blink: Auditory entrainment improves conscious visual processing. Psychological Research,80, 774-784. doi:10.1007/s00426-015-0691-8

Ruffino, M., Gori, S., Boccardi, D., Molteni, M., \&Facoetti, A. (2014). Spatial and temporal attention in developmental dyslexia. Frontiers in Human Neuroscience, 8, 331. doi:10.3389/fnhum.2014.00331

Ruffino, M., Trussardi, A.N., Gori, S., Finzi, A., Giovagnoli, S., Menghini, ... Facoetti, A. (2010). Attentional engagement deficits in dyslexic children. Neuropsychologia, 48 , 3793-3801. doi:10.1016/j.neuropsychologia.2010.09.002 
Ruzzoli, M., Gori, S., Pavan, A., Pirulli, C., Marzi, C.A., \&Miniussi, C. (2011). The neural basis of the Enigma illusion: A transcranial magnetic stimulation study. Neuropsychologia, 49, 3648-3655. doi:10.1016/j.neuropsychologia.2011.09.020

Schneider, K. A., \& Kastner, S. (2009). Effects of sustained spatial attention in the human lateral geniculate nucleus and superior colliculus. Journal of Neuroscience, 29, 17841795. doi:10.1523/JNEUROSCI.4452-08.2009

Schneps, M. H., Thomson, J. M., Chen, C., Sonnert, G., \&Pomplun, M. (2013). E-readers are more effective than paper for some with dyslexia. PLoS ONE, 8(9), e75634. doi:10.1371/journal.pone.0075634

Schneps, M. H., Thomson, J. M., Sonnert, G., Pomplun, M., Chen, C., \& Heffner-Wong, A. (2013). Shorter lines facilitate reading in those who struggle. PLoS ONE, 8(8), e71161.doi:10.1371/journal.pone.0071161

Schulte-Körne, G., \&Bruder, J. (2010). Clinical neurophysiology of visual and auditory

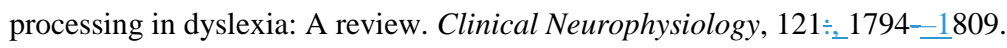
doi:10.1016/j.clinph.2010.04.028.

Spinelli, D., De Luca, M., Judica, A., \&Zoccolotti, P. (2002). Crowding effects on word identification in developmental dyslexia. Cortex, 38, 179-200.

Stein, J. (2012). Visual contributions to reading difficulties: The Magnocellular theory. In Stein, J., Kapoula, Z. (Eds.), Visual aspect of dyslexia (pp. 171-197). Oxford, UK: Oxford University Press.

Stein, J. (2014). Dyslexia: The role of vision and visual attention. Current Developmental Disorders Reports, 1, 267-280.

Stein, J., \& Walsh, V. (1997). To see but not to read: The magnocellular theory of dyslexia.Trends in Neurosciences, 20, 147-152. 
Stevens, C., Fanning, J., Donna, C., Sanders, L.,\& Neville, H. (2008). Neural mechanisms of selective auditory attention are enhanced by computerized training:

Electrophysiological evidence from language-impaired and typically developing children. Brain Research,1205, 55-69. doi:10.1016/j.brainres.2007.10.108

Takashima, A., Wagensveld, B., van Turennout, M., Zwitserlood, P., Hagoort, P., \& Verhoeven, L.(2014). Training-induced neural plasticity in visual-word decoding and the role of syllables. Neuropsychologia, 61, 299-314. doi:10.1016/j.neuropsychologia.2014.06.017

Tallal, P. (2004). Improving language and literacy is a matter of time. Nature Reviews Neuroscience, 5, 721-728.

Tallal, P., Miller, S.L., Bedi, G., Byma, G., Wang, X., Nagarajan, S.S., ...Merzenich, M.M. (1996). Language comprehension in language-learning impaired children improved with acoustically modified speech. Science, 271, 81-84.

Turkeltaub, P. E., Gareau, L., Flowers, D. L., Zeffiro, T. A., \& Eden, G. F. (2003).

Development of neural mechanisms for reading. Nature Neuroscience, 6, 767-773. doi:10.1038/nn1065

Valdois, S., Bosse, M.L., \&Tainturier, M. J. (2004). The cognitive deficits responsible for developmental dyslexia: Review of evidence for a selective visual attentional disorder. Dyslexia, 10, 339-363. doi:10.1002/dys.284

Vellutino, F.R., Fletcher, J.M., Snowling, M.J., \& Scanlon, D.M. (2004). Specific reading disability (dyslexia): What have we learned in the past four decades?Journal of Child Psychology and Psychiatry, 45, 2-40. doi:10.1046/j.0021-9630.2003.00305.x

Vidyasagar, T.R. (1999). A neuronal model of attentional spotlight: Parietal guiding the temporal. Brain Research Reviews, 30, 66-76. doi:10.1016/S0165-0173(99)00005-3 
Vidyasagar, T.R. (2013). Reading into neuronal oscillations in the visual system:Implications for developmental dyslexia. Frontiers in Human Neuroscience, $7,811$. doi:10.3389/fnhum.2013.00811

Vidyasagar, T.R., \& Pammer, K. (2010). Dyslexia: A deficit in visuo-spatial attention, not in phonological processing. Trends in Cognitive Sciences, 14, 57-63. doi:10.1016/j.tics.2009.12.003

Virsu, V., Lahti-Nuuttila, P., \& Laasonen, M. (2003). Crossmodal temporal processing acuity impairment aggravates with age in developmental dyslexia. Neuroscience Letters, 336, 151-154. doi:10.1016/S0304-3940(02)01253-3

Vogel, A.C., Miezin, F.M., Petersen, S.E., \& Schlaggar, B.L. (2012). The putative visual word form area is functionally connected to the dorsal attention network. Cerebral Cortex, 22,537-549. doi:10.1093/cercor/bhr100

Walsh, V. (1995). Dyslexia: Reading between the laminae. Current Biology, 5,1216-1217.

Whitney, D., \& Levi, D.M. (2011). Visual crowding: A fundamental limit on conscious perception and object recognition. Trends in Cognitive Sciences, 15, 160-168.

Wright, C. M., Conlon, E. G., \& Dyck, M. (2012). Visual search deficits are independent of magnocellular deficits in dyslexia. Annals of dyslexia, 62, 53-69.

Witton, C., Talcott, J.B., Hansen, P.C., Richardson, A.J., Griffiths, T.D., Rees, A., ... Green, G. G. R. (1998). Sensitivity to dynamic auditory and visual stimuli predicts nonword reading ability in both dyslexic and normal readers. Current Biology, 8,791-797.

Yazdanbakhsh, A., \& Gori, S. (2011). Mathematical analysis of the accordion grating illusion: Adifferential geometry approach to introduce the 3D aperture problem. Neural Networks, 24, 1093-1101. doi:10.1016/j.neunet.2011.06.016

Yu, D., Cheung, S.H., Legge, G.E., \& Chung S.T.L. (2007). Effect of letter spacing on visual span and reading speed. Journal of Vision, 7:2, 1-10. doi:10.1167/7.2.2 
Zhao, J., Qian, Y., Bi, H.Y.,\& Coltheart, M. (2014). The visual magnocellular-dorsal dysfunction in Chinese children with developmental dyslexia impedes Chinese character recognition. Scientific Reports, 4, 7068, 1-7. doi:10.1038/srep07068

Zorzi, M., Barbiero, C., Facoetti, A., Lonciari, I., Carrozzi, M., Montico, M., ... Ziegler, J. C. (2012). Extra-large letter spacing improves reading in dyslexia. Proceedings of the National Academy of Sciences of the United States of America, 109, 11455-11459. doi:10.1073/pnas.1205566109.

Ziegler, J. C., Pech-Georgel, C., George, F., Alario, F. X., \& Lorenzi, C. (2005). Deficits in speech perception predict language learning impairment. Proceedings of the national academy of sciences of the united states of america, 102, 14110-14115. 